\title{
Antiretroviral Treatment Failure and Associated Factors Among HIV-Infected Children on Antiretroviral Therapy: A Retrospective Study
}

This article was published in the following Dove Press journal: HIVIAIDS - Research and Palliative Care

\author{
Solomon Getawa' \\ Abaynesh Fentahun ${ }^{2}$ \\ Tiruneh Adane $\mathbb{I D}^{1}$ \\ Mulugeta Melku (D) \\ 'Department of Hematology and \\ Immunohematology, School of \\ Biomedical and Laboratory Sciences, \\ College of Medicine and Health Sciences, \\ University of Gondar, Gondar, Ethiopia; \\ ${ }^{2}$ Department of Clinical Pharmacy, \\ School of Pharmacy, College of Medicine \\ and Health Sciences, University of \\ Gondar, Gondar, Ethiopia
}

Background: HIV/AIDS-associated morbidity and mortality have reduced since the introduction of antiretroviral therapy (ART). Treatment failure is one of the causes of mortality, morbidity, and the development of drug-resistant viral strains. Therefore, this research aims to assess the prevalence and associated factors of treatment failure among children with HIV/ AIDS on antiretroviral therapy attending the University of Gondar Specialized Referral Hospital, Northwest Ethiopia.

Methods: A retrospective study was conducted on 200 children registered for ART from 2005 to 2017. Data regarding patients' socio-demographic, baseline clinical characteristics, and treatment-related information were collected through a review of their medical records. Data were entered into Epi-info version 3.5.3 and analyzed using statistical package for social sciences (SPSS) version 21 software. To summarize characteristics of the study participant's descriptive statistics were done. Bivariable and multivariable binary logistic regression were fitted to identify factors associated with treatment failure. The odds ratio and $95 \%$ confidence interval (CI) were calculated to assess the strength of the association and P-value $<0.05$ in the multivariable regression was considered as statistically significant.

Results: The prevalence of ART failure was $12.5 \%$ (95\% CI: 7.88, 17.12), clinical failure was the most common followed by immunologic failure with only a small proportion having both clinical and immunologic failure. The mean time to develop treatment failure after initiation of the first-line regimen was $22.28 \pm 24.00$ months. Being male $(\mathrm{AOR}=3.15 ; 95 \%$ CI: 1.18-8.39), co-infected with tuberculosis (TB) at baseline $(\mathrm{AOR}=2.37 ; 95 \% \mathrm{CI}: 1.23--$ $8.84)$, being on ART for a long period ( $>36$ months) (AOR $=1.01 ; 95 \% \mathrm{CI}: 1.34-2.89)$, and regimen change $(\mathrm{AOR}=9.22 ; 95 \% \mathrm{CI}: 3.36-25.03)$ were factors of ART failure.

Conclusion: In this study, there is significant treatment failure among HIV-infected children. Having co-infection, being on ART for a long period, regimen change, and being male were found to be independent factors of treatment failure in children. Therefore, timely identification and monitoring of ART failure should be necessary to enhance the benefit and to prevent further complications. Prophylaxis for opportunistic infections such as co-trimoxazole preventive therapy should continue to recover the immunological status of the child.

Keywords: HIV/AIDs, antiretroviral, treatment failure, associated factors, Ethiopia

\section{Background}

Acquired immunodeficiency syndrome (AIDS) is disease caused by virus called human immunodeficiency virus (HIV). ${ }^{1}$ There were approximately 38 million people worldwide living with HIV/AIDS in 2019. Of these, 1.8 million were children ( $<15$ years old): among them, an estimated 28\% live in Eastern and southern Africa. In 2019, around
Department of Hematology and Immunohematology, School of Biomedica and Laboratory Sciences, College of Medicine and Health Sciences, University of Gondar, Ethiopia P. O. BOX: 196 Tel +25I-949-914-917

Email tirunehadane0I@gmail.com 
1.7 million individuals were newly infected with HIV globally. Of these, 150, 000 were children aged 0-14 years. Most of these children lived in sub-Saharan Africa and were infected by their HIV-positive mothers during pregnancy, childbirth, or breastfeeding. ${ }^{2}$ The Joint United Nations Program on HIV and AIDS 90-90-90 targets the goal of achieving viral suppression in $90.0 \%$ of the individuals on sustained ART. ${ }^{3}$ Based on the United Nations HIV/AIDS report, about 690,000 (530,000900,000) people were living with HIV/AIDS in Ethiopia in 2018. Of them, $36,000(23,000-55,000)$ were children aged 0-14 years; of which 21,500 (59\%) of them were receiving ART. $^{4}$

ART are drugs used in combination of three or more antiretroviral drugs from different classes such as: entry inhibitors, nucleoside and non-nucleoside analog inhibitors of reverse transcriptase, integrase inhibitors, and protease inhibitors, either taken individually or in fixed-dose combinations for the treatment of HIV. ${ }^{5}$ ART failure is defined as progression of the disease and high risk of mortality after the beginning of ART. It can be assessed by clinical failure, immunologic failure, and virological failure. ${ }^{6-8}$ In the absence of viral load test, treatment failure has been assessed using clinical and immunological criteria. ${ }^{1,9-11}$

Pediatric ART failure is an under-recognized issue that receives inadequate attention in HIV treatment programs. Pediatric ART failure rates range from $19.3 \%$ to over $32.0 \%$ in resource-limited settings. ${ }^{12}$ The current systematic review and meta-analysis showed that the overall HIV treatment failure in Ethiopia was $15.9 \%$. The pooled treatment failure in children was $14.6 \%$. Of the total, $10.2 \%$, $5.6 \%$, and $6.3 \%$ were immunological, virological, and clinical treatment failure, respectively. World Health Organization (WHO) clinical stage III/IV, opportunistic infections, low CD4 cell count, and poor adherence to ART were the identified associated factors for treatment failure. $^{13}$

The identification and management of first-line ART failure is a key challenge for HIV programs in a resourcelimited setting. Staying on a failing first-line therapy is associated with an increased risk of mortality. ${ }^{10}$ Increasing the duration of children stay on a failing regimen results in drug resistance and potentially enhances morbidity and mortality. ${ }^{14}$ Therefore, to increase the efficacy rate of ART, the prevalence and factors of treatment failure among children on first-line ART should be identified. The finding encourages clinicians to provide targeted treatment approach which provides appropriate treatment care and follow up for HIV infected children.

\section{Materials and Methods}

\section{Study Area}

The study was conducted at the University of Gondar Specialized Referral Hospital. The hospital is found in Gondar town, Amhara regional state at $738 \mathrm{~km}$ from the capital city of Ethiopia, Addis Ababa. It is situated at 2133 meters above sea level. The ART service of the hospital was initiated in 2005, and it has 7 outpatient rooms, one voluntary testing and counseling room, one pharmacy, and one laboratory. The ART service has three adult ART clinics, one pediatric, one voluntary counseling, and 2 adherence counseling clinics. Based on the information obtained from the hospital, since the hospital started ART service, 7581 adults and 738 pediatric HIV-infected patients had been enrolled for ART service until the end of 2016.

\section{Study Design, Period and Population}

An institution-based retrospective cross-sectional study was conducted from March to May 2017. The medical records of HIV-infected children who registered for ART from 2005 to 2017 were the source population. Medical records of HIV-infected children who took ART for at least six months at the University of Gondar specialized referral hospital ART clinic were the study population.

\section{Sample Size and Sampling Technique}

Because tThe study was a retrospective, the sample size calculation was not applicable. A total of 540 HIV-infected children who were taking ART were registered. From those children, 200 of them who took ART for at least 6 months and had complete information for key variables were included in this study.

\section{Inclusion and Exclusion Criteria}

All medical records of HIV-infected children who took ART for at least 6 months at the University of Gondar specialized referral hospital ART clinic were included; whereas those HIV-infected children with incomplete data on hemoglobin (Hgb), CD4 count, WHO clinical stage, ART adherence, type of regimen, weight, height, and age were excluded from the study.

\section{Study Variables}

The dependent variable of the study was treatment failure. The independent variables include socio-demographic characteristics of children and their caregivers (age, sex, religion, marital status, level of education, occupational status, and 
parental survival status), medical conditions and laboratory data (CD4 cell count, Hgb level, functional status, WHO clinical stages, and opportunistic infections), and treatmentrelated data (ART regimens, adherence to ART and year of ART initiation).

\section{Operational Definition}

Treatment failure: is categorized as a clinical, immunological, and virological failure and defined as follows. ${ }^{6,15}$

Clinical failure: New or recurrent clinical event indicating an advanced or severe immune deficiency (WHO clinical stage III and IV clinical conditions with exception of TB) after 6 months of effective treatment.

Immunological failure: CD4 count falls to the baseline or persistent CD4 levels below 100 cells/mm3 for adult and adolescent or below 200 cells $/ \mathrm{mm} 3$ in younger than 5 years. Virological failure: Plasma viral load above 1000 copies/ $\mathrm{mL}$ based on two consecutive viral load measurements in 3 months, with adherence support following the first viral load test.

Adherence: The extent to which a client's behavior coincides with the prescribed regimen. ${ }^{6}$ Based on the remaining pill count clinicians can consider good adherence $(<95 \%)$ if the patient miss to take $\leq 2$ of 30 prescribed doses, fair adherence (85-94\%) if the patient miss to take $3-5$ of 30 prescribed doses, and poor adherence $(<85 \%)$ if the patient miss to take less than 6 of 30 prescribed doses. ${ }^{14,15}$

Functional status: defined as working/appropriate (the ability to perform usual work in and out of the house), ambulatory/delayed (the ability to perform activities of daily living), and bedridden/regression (not able to perform activities). ${ }^{16}$

\section{Data Collection Tools and Procedure}

Data were collected using structured questionnaires which were adopted from the Ethiopian Federal Ministry of Health National Guidelines for Comprehensive HIV Prevention, Care and Treatment, 2014. ${ }^{17}$ The tool was further customized based on the children ART monitoring record book. The following data was collected from the patients' medical records like socio-demographic status, Hgb value, weight, height, CD4 cell count, type of ART regimens used, WHO clinical stages, TB screening results, ART adherence, and other clinical characteristics at baseline and after ART initiation.

\section{Data Analysis and Interpretation}

Data were cleared, entered into Epi-info version 3.5.3, and then transferred to Statistical Package for Social
Science (IBM Corporation, Armonk, NY, USA) version 20 software for analysis. Descriptive statistics were used to summarize characteristics of the study participants through tables. A bivariable binary logistic regression model was fitted to identify factors associated with treatment failure. Hosmer-Lemeshow goodness-of-fit test was used to assess the fitness of the model. Predictor variables having a p-value less than or equals to 0.2 in the bi-variable analysis were included in the multi-variable analysis to control confounders. Both crude odds ratio (COR) and adjusted odds ratio (AOR) with the corresponding 95\% CI were calculated to show the strength of association. A p-value $<0.05$ in the multi-variable regression model was considered as statistically significant.

\section{Ethical Consideration}

The study was conducted after approval of the protocol by the Ethical Review Committee of School of Biomedical and Laboratory Sciences, College of Medicine and Health Sciences, the University of Gondar. A permission letter was also granted from the chief clinical director of the University of Gondar Specialized Referral Hospital. The information obtained from the participants were coded to ensure confidentiality. Since it was a retrospective study from medical records, a consent waiver to participate in the study was obtained from ethical review board.

\section{Result}

\section{Socio-Demographic Characteristics}

A total of 200 medical records of HIV-infected children on ART were reviewed. The mean $\pm \mathrm{SD}$ (standard deviation) age of the patients at the enrollment of the ART clinic was $52.9 \pm 31.2$ months. More than half of the participants, 117 $(58.5 \%)$ were females and 181 (90.5\%) were from urban areas. Regarding caregivers' marital status, 150 (75.0\%) were married and $134(67.0 \%)$ of the caregivers had biological relationship with a child. Sixty two $(31.0 \%)$ of the caregivers were positive for HIV (Table 1).

\section{Clinical and Treatment-Related Characteristics}

Out of study participants, 80 (40.0\%) started ART based on both clinical and CD4 eligibility criteria. One hundred five $(52.5 \%)$ of the participants started ART from 2005-2012 years, while 95 (45.5\%) were started ART from 2013-2017 years. The predominant ART regimen initially prescribed for them were a combination of 
Table I Socio-Demographic Characteristics of HIV-Infected Children Who Were on ART and Their Caregivers at University of Gondar Specialized Referral Hospital from 2005 to 2017

\begin{tabular}{|c|c|c|c|}
\hline Characteristics & Category & Frequency & Percentage \\
\hline \multirow{3}{*}{$\begin{array}{l}\text { Age at enrolment } \\
\text { (years) }\end{array}$} & $<5$ & 118 & 59.0 \\
\hline & $5-9$ & 73 & 36.5 \\
\hline & $10-15$ & 9 & 4.5 \\
\hline \multirow[t]{2}{*}{ Sex } & Male & 83 & 41.5 \\
\hline & Female & 117 & 58.5 \\
\hline \multirow[t]{2}{*}{ Residence } & Urban & 181 & 90.5 \\
\hline & Rural & 19 & 9.5 \\
\hline \multirow{3}{*}{$\begin{array}{l}\text { Caregiver's marital } \\
\text { status }\end{array}$} & Single & 18 & 9.0 \\
\hline & Married & 150 & 75.0 \\
\hline & $\begin{array}{l}\text { Widowed/ } \\
\text { divorced }\end{array}$ & 32 & 16.0 \\
\hline \multirow[t]{2}{*}{$\begin{array}{l}\text { Caregiver's } \\
\text { educational status }\end{array}$} & $\begin{array}{l}\text { Unable to read } \\
\text { and write }\end{array}$ & 59 & 29.5 \\
\hline & $\begin{array}{l}\text { Primary } \\
\text { school }\end{array}$ & $|4|$ & 70.5 \\
\hline \multirow[t]{5}{*}{$\begin{array}{l}\text { Caregiver's } \\
\text { occupation }\end{array}$} & $\begin{array}{l}\text { Government } \\
\text { employed }\end{array}$ & 13 & 6.5 \\
\hline & Farmer & 7 & 3.5 \\
\hline & Merchant & 54 & 27.0 \\
\hline & Housewife & 78 & 39.0 \\
\hline & Daily laborer & 48 & 24.0 \\
\hline \multirow{2}{*}{$\begin{array}{l}\text { Caregiver's } \\
\text { relationship with } \\
\text { child }\end{array}$} & Biological & 134 & 67.0 \\
\hline & Relatives & 66 & 33.0 \\
\hline \multirow{3}{*}{$\begin{array}{l}\text { Caregiver's HIV } \\
\text { status }\end{array}$} & Positive & 62 & 31.0 \\
\hline & Negative & 8 & 4.0 \\
\hline & Unknown & 130 & 65.0 \\
\hline \multirow[t]{4}{*}{ Parent status } & Either live & 52 & 26.0 \\
\hline & Both live & 75 & 37.5 \\
\hline & Neither live & 3 & 1.5 \\
\hline & Unknown & 70 & 35.0 \\
\hline
\end{tabular}

Abbreviation: HIV, human immunodeficiency virus.

Zidovudine (AZT) + Lamivudine (3TC) + Nevirapine (NVP)/Efavirenz (EFV) in $130(65.0 \%)$ of the children. Forty nine $(24.5 \%)$ of the children initially initiated with a combination of Stavudine (D4T) + 3TC + NVP ART regimen, followed by Tenofovir (TDF) $+3 \mathrm{TC}+$ EFV. One hundred twenty-nine $(64.5 \%)$ of study participants were WHO clinical stage I and II at the time of ART initiation and $18(9 \%)$ of the children had a history of TB treatment at initiation of ART. Half, 105 (52.5\%) of the participants were on ambulatory/delayed functional status at a baseline. Seventy five (37.5\%) of the participants had anemia at initiation of ART. The mean \pm SD weight of the children at the initiation of ART and last visit of follow-up were $15 \mathrm{~kg} \pm 6.5 \mathrm{~kg}$ and $23.3 \mathrm{~kg} \pm 9.9 \mathrm{~kg}$, respectively. The baseline and current median $\mathrm{CD} 4^{+}$cell counts were 526 cells $/ \mathrm{mm}^{3}$ (interquartile range (IQR): $314.50-526.00$ ) and 859.50 cells $/ \mathrm{mm}^{3}$ (IQR: 622.50-859.50), respectively. Participants were on first-line ART with a median follow up time of 45.5 months (IQR: 25.5-45.5) (Table 2).

\section{Prevalence of ART Failure}

Treatment failure was assessed based on clinical and immunological failure WHO criteria. The overall prevalence of ART failure was 12.5\% (95\% CI: 7.88, 17.12). Among participants with failure, 18 (72.0\%), 4 (16.0\%), and $3(12.0 \%)$ had clinical, immunological, and both immunological and clinical failure, respectively. The mean time to develop treatment failure after initiation of the first-line regimen was $22.28 \pm 24.00$ months with a range from 6 to 37 months. The majority, $16(64 \%)$ of treatment failures had occurred among clients who were on ART for $\geq 12$ months.

\section{Factors Associated with Treatment Failure}

Bivariate and multivariate analysis was conducted to determine predictor variables of treatment failure. In bivariate analysis male children, children infected with opportunistic infection (TB) at baseline, children on ART for a long period (>36 months), children with ZDV+3TC+NVP/EVF initial regimen, children with a long time lag since HIV diagnosis and start of ART (>12 months), children with regimen change were significantly associated with treatment failure. Being male $(\mathrm{AOR}=3.15 ; 95 \%$ CI: 1.18-8.39), children infected with opportunistic infection (TB) at baseline $(\mathrm{AOR}=2.37 ; 95 \% \mathrm{CI}: 1.23-8.84)$, being on ART for a long period ( $>36$ months) (AOR $=1.47 ; 95 \%$ CI: $1.34-$ 2.89), regimen change ( $\mathrm{AOR}=9.22 ; 95 \% \mathrm{CI}: 3.36-25.03$ ) were significantly associated with treatment failure in multivariable logistic regression analysis model (Table 3). 
Table 2 Clinical and Treatment-Related Characteristics of HIV-Infected Children Who Were on ART at University of Gondar Specialized Referral Hospital from 2005 to 2017

\begin{tabular}{|c|c|c|c|}
\hline Characteristics & Category & Frequency & Percentage \\
\hline \multirow[t]{3}{*}{ Eligibility criteria for ART initiation } & Clinical only & 70 & 35.0 \\
\hline & CD4 only & 50 & 25.0 \\
\hline & Both clinical and CD4 & 80 & 40.0 \\
\hline \multirow[t]{2}{*}{ Year of ART start } & $2005-2012$ & 105 & 52.5 \\
\hline & $2013-2017$ & 95 & 47.5 \\
\hline \multirow[t]{2}{*}{ WHO clinical stage } & Stage I & \multirow[t]{2}{*}{$\&$ II } & 129 \\
\hline & 64.5 & & \multirow[b]{3}{*}{44.5} \\
\hline Stage III \&IV & 71 & 35.5 & \\
\hline \multirow[t]{3}{*}{ Functional status } & Working/appropriate & 89 & \\
\hline & Ambulatory/delayed & 105 & 52.5 \\
\hline & Bed driven/regression & 6 & 3.0 \\
\hline \multirow[t]{2}{*}{ TB treatment history } & Yes & 18 & 9.0 \\
\hline & No & 182 & 91.0 \\
\hline \multirow[t]{2}{*}{ INH preventive therapy on ART initiation } & Yes & 8 & 4.0 \\
\hline & No & 192 & 96.0 \\
\hline \multirow[t]{2}{*}{ Ols on ART initiation } & Yes & 7 & 3.5 \\
\hline & No & 193 & 96.5 \\
\hline \multirow[t]{3}{*}{ Initial regimen } & $A Z T+3 T C+N V P$ & 49 & 24.5 \\
\hline & $Z D V+3 T C+N V P / E V F$ & 130 & 65.0 \\
\hline & $\mathrm{TDF}+3 \mathrm{TC}+\mathrm{EVF}$ & 21 & 10.5 \\
\hline \multirow[t]{2}{*}{ Duration on ART (months) } & $\leq 36$ & 80 & 40.0 \\
\hline & $>36$ & 120 & 60.0 \\
\hline \multirow[t]{3}{*}{ Time lag since HIV diagnosis and start of ART } & Same month & 36 & 18.0 \\
\hline & $1-12$ months & 110 & 55.0 \\
\hline & $>12$ months & 54 & 27.0 \\
\hline \multirow[t]{2}{*}{ Regimen change } & Yes & 54 & 27.0 \\
\hline & No & 146 & 73.0 \\
\hline \multirow[t]{2}{*}{ Base line weight at ART initiation } & $\leq 15 \mathrm{~kg}$ & 118 & 59.0 \\
\hline & $>15 \mathrm{~kg}$ & 82 & 41.0 \\
\hline \multirow[t]{2}{*}{ CD4 count at ART initiation } & $\leq 200$ cells $/ \mathrm{mm} 3$ & 26 & 13.0 \\
\hline & $>200$ cells $/ \mathrm{mm} 3$ & 174 & 87.0 \\
\hline \multirow[t]{2}{*}{ Anemia at ART initiation } & Yes & 75 & 37.5 \\
\hline & No & 125 & 62.5 \\
\hline
\end{tabular}


Table 2 (Continued).

\begin{tabular}{|l|l|l|l|}
\hline Characteristics & Category & Frequency & Percentage \\
\hline Current CD4 count & $\leq 200$ cells $/ \mathrm{mm} 3$ & 1 & 0.5 \\
\cline { 2 - 4 } & $>200$ cells $/ \mathrm{mm} 3$ & 199 & 99.5 \\
\hline ART adherence & Good & 193 & 96.5 \\
\cline { 2 - 4 } & Poor & 7 & 3.5 \\
\hline
\end{tabular}

Abbreviations: ART, antiretroviral therapy; CD, cluster of differentiation; INH, isoniazid prophylaxis; HIV, human immunodeficiency virus; Ols, opportunistic infections; TB, tuberculosis; WHO, World Health Organization; AZT, zidovudine; 3TC, lamivudine; NVP, nevirapine; D4T, stavudine; TDF, tenofovir; EFV, efavirenz.

\section{Discussion}

The increased availability of ART has led to dramatically improved survival rates and lowered the incidence of opportunistic infections in people with HIV. Even though ART are not a cure for HIV, it prevent HIV from multiplying rapidly, and at the same time, boost the body's immune system and increase the quality of life. ${ }^{18}$

In the current study, the prevalence of ART failure among children was $12.5 \%$ (95\% CI: 7.88, 17.12), clinical failure was the most common followed by immunologic failure with only a small proportion having both clinical and immunologic failure. The current finding is consistent with the finding reported at four ART center hospitals; Addis Ababa (14.1\%), ${ }^{19}$ Amhara Region Referral Hospitals $(12.19 \%),{ }^{14}$ Jimma University Hospital $(11.5 \%),{ }^{20}$ and current systematic review and metaanalysis in Ethiopia (15.3\%). ${ }^{21}$ On the other hand, the finding is lower than the prevalence reported in the previous study conducted in University of Gondar specialized referral Hospital (18.2\%), ${ }^{22}$ Tikur Anbessa Specialized Hospital $(22.6 \%),{ }^{23}$ Fiche and Kuyu hospital in the Oromia region $(18.9 \%),{ }^{24}$ Ghana $(29 \%),{ }^{25}$ Tanzania $(57 \%),{ }^{26}$ and Uganda and Mozambique $(29 \%) .{ }^{27}$ The possible explanation could be the current study does not include virological failures as viral load testing is not routinely available; this could underestimate the greater impact of virological failure. The mean time to develop treatment failure after initiation of the first-line regimen was $22.28 \pm 24.00$ months, which is similar to study done in Addis Ababa, Ethiopia (19.7 \pm 14 months $).{ }^{28}$ On the contrary, it is less than the study done in Fiche and Kuyu hospital in Oromia region $(41 \pm 24.96 \text { months })^{24}$ and longer than the study conducted in South Africa ${ }^{29}$ and in Malawi. ${ }^{30}$ Frequent machine failure to determine CD4 cell count and viral load testing service to support diagnosis and lack of trained health care providers to identify early evidence of treatment failure could be the possible factors contributing to the delay.

This research identifies that children with opportunistic infections like TB have higher odds of first-line ART failure ( $\mathrm{AOR}=2.37,95 \%$ CI: 1.23-8.84), which is in line with previous studies conducted in the University of Gondar specialized referral Hospital, ${ }^{22}$ Jimma University Specialized Hospital, $^{31}$ and four ART center hospitals in Addis Ababa. ${ }^{19}$ The possible explanation could be that people living with HIV and with TB have confounding factors such as; overlapping drug toxicities, exacerbation of side effects, reduce adherence to prescribed medication, and immune reconstitution inflammatory syndrome. ${ }^{32}$ TB weakens the immune system, which in turn facilitates viral replication. ${ }^{33}$ HIV-infected patients with opportunistic infection may interrupt the time of taking a drug, lost follow-up, and other triple problems that lead to HIV treatment failure.

The other factor associated with treatment failure in this study was sex. Being male has higher odds of ART failure $(\mathrm{AOR}=3.15 ; 95 \% \mathrm{CI}: 1.18-8.39)$, which is similar to a previous study conducted in Senegal ${ }^{34}$ and Uganda. ${ }^{35}$ The possible reason suggested by Penot et al related to sex differences in pharmacokinetics and pharmacodynamics profiles of antiretroviral drugs. Higher concentrations of ART drugs which favor virological efficacy have been observed in female than male. ${ }^{36}$

The risk of treatment failure was nine times higher among patients those changed ART regimen as compared to those who did not change ART regimen (AOR $=9.22$ : 95\% (3.36-25.03)). This finding was in agreement with previous studies conducted in Ethiopia ${ }^{19,21,22,37}$ and Malawi. ${ }^{30}$ This might be due to the patient clinical background/condition that may force them to change the regimen.

Children who had been on long-duration of ART treatment had a higher risk of treatment failure than their counterparts (AOR=1.47: 95\% (1.34-2.89)). This finding 
Table 3 Logistic Regression Analysis of Treatment Failure and Explanatory Variables Among HIV-Infected Children Who Were on ART at University of Gondar Specialized Referral Hospital from 2005 to 2017

\begin{tabular}{|c|c|c|c|c|c|}
\hline \multirow[t]{2}{*}{ Characteristics } & \multirow[t]{2}{*}{ Category } & \multicolumn{2}{|c|}{ Treatment Failure } & \multirow[t]{2}{*}{ COR $(95 \% \mathrm{Cl})$} & \multirow[t]{2}{*}{$\operatorname{AOR}(95 \mathrm{Cl})$} \\
\hline & & Yes N (\%) & No $\mathbf{N}(\%)$ & & \\
\hline \multirow[t]{2}{*}{ Sex } & Male & $14(16.9)$ & $69(83.1)$ & $1.96(0.84-4.46)$ & $3.15(1.18-8.39)^{*}$ \\
\hline & Female & II (9.4) & $106(90.6)$ & $I^{*}$ & $I^{*}$ \\
\hline \multirow[t]{2}{*}{ WHO clinical stage on initiation } & Stage I and II & $13(10.1)$ & $116(89.9)$ & $I^{*}$ & - \\
\hline & Stage III and IV & $12(16.9)$ & $59(83.1)$ & $1.82(0.78-4.23)$ & $1.14(0.39-3.26)$ \\
\hline \multirow[t]{2}{*}{ TB treatment history } & Yes & $5(27.8)$ & $13(72.2)$ & $3.12(1.01-6-65)$ & $2.37(1.23-8.84)^{*}$ \\
\hline & No & $20(11.0)$ & $162(89.0)$ & $I^{*}$ & $I^{*}$ \\
\hline \multirow[t]{3}{*}{ Initial regimen } & $A Z T+3 T C+N V P$ & $7(14.3)$ & $42(85.7)$ & $1.58(0.30-8.34)$ & - \\
\hline & $Z D V+3 T C+N V P / E V F$ & $16(12.3)$ & II $4(87.7)$ & $1.34(0.28-6.27)$ & - \\
\hline & $T D F+3 T C+E V F$ & $2(9.5)$ & $19(90.5)$ & $I^{*}$ & \\
\hline \multirow[t]{2}{*}{ Duration on ART (months) } & $\leq 36$ & $7(8.8)$ & $73(91.3)$ & $I^{*}$ & $I^{*}$ \\
\hline & $>36$ & $18(15.0)$ & $102(85.0)$ & $1.84(0.73-4.63)$ & $1.47(1.34-2.89)^{*}$ \\
\hline \multirow[t]{3}{*}{ Time lag since HIV diagnosis and start of ART } & Same month & $3(8.3)$ & $33(91.7)$ & $I^{*}$ & \\
\hline & I-12 months & I3 (1 I.8) & $97(88.2)$ & $1.47(0.39-5.45)$ & - \\
\hline & $>12$ months & $9(16.7)$ & $45(83.3)$ & $2.20(0.55-8.76)$ & - \\
\hline \multirow[t]{2}{*}{ Regimen change } & Yes & $17(3 \mid .5)$ & $37(68.5)$ & $7.92(3.17-19.80)$ & $9.22(3.36-25.03)^{*}$ \\
\hline & No & $8(5.5)$ & $138(94.5)$ & $I^{*}$ & $I^{*}$ \\
\hline
\end{tabular}

Notes: I* indicates the constant category, * indicates the significant level at $\mathrm{p}<0.05$.

Abbreviations: AOR, adjusted odds ratio; ART, antiretroviral therapy; COR, crude odds ratio; Cl, confidence interval; HIV, human immunodeficiency virus; TB, tuberculosis; WHO, World Health Organization; AZT, zidovudine; 3TC, lamivudine; NVP, nevirapine; D4T, stavudine; TDF, tenofovir; EFV, efavirenz.

was in line with previous studies conducted in Ethiopia $^{11,37,38}$ and Bangalore. ${ }^{39}$ The possible reason could be if the duration of ART increases, the emergence of HIV-drug resistance mutation and persistent HIV- replication occurred. $^{40,41}$ Besides, as the duration of ART increases, the likelihood of poor adherence, drug interruption, and drug side effects also increases. Thus, a high burden of a drug-resistant virus with an increased viral load is expected among patients with more months than with lesser months on ART. ${ }^{37,41}$ Those who took the drug for a long duration of time may develop drug side effects and resistance easily.

The study found that only a small proportion $(3.5 \%)$ of the children had poor adherence to ART regimens. In this study, poor adherence is not significantly associated with treatment failure which is against other findings from Ethiopia, ${ }^{24,42}$ Tanzania, ${ }^{43}$ and Uganda. ${ }^{44}$ A study done by Sibhat et al revealed that poor adherence was a risk factor for treatment failure because a high level of adherence is necessary to suppress viral replication and improve immunological and clinical outcomes which in turn decrease the risk of developing drug resistance to HIV. ${ }^{42}$ The high adherence rate in the current study which could be explained by the retrospective nature of the study is affected by infrequent measurements, lost pills, and discard pills.

\section{Limitation of the Study}

Since the study was a retrospective study; the data were extracted from routine medical records may have been incomplete, inconclusive, or inaccurate. Deaths, dropouts, and transfer out patients were not included and this could have biased our estimates. Lack of a viral load test may also potentially limit magnitude of treatment failure in this study.

\section{Conclusion}

There is a significant magnitude of ART failure among children in the study area. Clinical failure was the most 
common followed by immunologic failure with only a small proportion having both clinical and immunologic failure. Being male, being on ART for a long period, regimen change, and being infected with opportunistic infection (TB) at initiation has identified the independent significant factors of treatment failure in children living with HIV/ AIDS after initiation of ART by this study. Therefore, timely and early identification of associated factors and monitoring ART treatment failure should be done to enhance the benefit and to prevent further complications.

\section{Abbreviations}

AIDS, acquired immunodeficiency syndrome; AOR, adjusted odds ratio; ART, antiretroviral therapy; CD, cluster of differentiation; CI, confidence interval; COR, crude odds ratio; Hgb, hemoglobin; HIV, human immunodeficiency virus; SD, standard deviation; TB, tuberculosis; AZT, zidovudine; 3TC, lamivudine; NVP, nevirapine; D4T, stavudine; TDF, tenofovir; EFV, efavirenz.

\section{Data Sharing Statement}

The data sets used and/or analyzed during the current study are available from the corresponding author on reasonable request.

\section{Ethical Approval}

The study was done after obtaining ethical clearance from School of Biomedical and Laboratory Sciences, College of Medicine and Health Sciences, University of Gondar. The study was also done as per the declaration of Helsinki.

\section{Disclosure}

The authors declare that there is no conflicts of interest in this work.

\section{References}

1. Kharsany AB, Karim QA. HIV infection and AIDS in sub-Saharan Africa: current status, challenges and opportunities. Open AIDS J. 2016;10(1):34. doi:10.2174/1874613601610010034

2. HIV/AIDS JUNPo. Global HIV \& AIDS statistics - 2020 fact sheet; 2020. Available from: www.unaidsorg/en/resources/fact-sheet. Accessed February 12, 2021.

3. Harries AD, Suthar AB, Takarinda KC, et al. Ending the HIV/AIDS epidemic in low-and middle-income countries by 2030: is it possible? F1000Research. 2016;5:2328. doi:10.12688/f1000research.9247.1

4. UNAIDS. Ethiopian-UNSAIDS. 2019. Available from: https://www. unsaids.org/en/regionscountries/countries/ethiopia. accessed on date $22 / 09 / 2020$
5. Blanco J, Clotet B. Learning from drug changes in antiretroviral therapy. Aids. 2013;27(5):833-834. doi:10.1097/QAD.0b013e32835c1213

6. Organization WH. Consolidated Guidelines on the Use of Antiretroviral Drugs for Treating and Preventing HIV Infection: Recommendations for a Public Health Approach. World Health Organization; 2016.

7. Aldous JL, Haubrich RH. Defining treatment failure in resource-rich settings. Curr Opin HIV AIDS. 2009;4(6):459. doi:10.1097/ COH.0b013e328331dea5

8. Ayele G, Tessema B, Amsalu A, Ferede G, Yismaw G. Prevalence and associated factors of treatment failure among HIV/AIDS patients on HAART attending University of Gondar Referral Hospital Northwest Ethiopia. BMC Immunol. 2018;19(1):37. doi:10.1186/ s12865-018-0278-4

9. Health FMo. National Guidelines for Comprehensive HIV Prevention, Care and Treatment. USAID; 2017.

10. Ayalew MB, Kumilachew D, Belay A, et al. First-line antiretroviral treatment failure and associated factors in HIV patients at the University of Gondar Teaching Hospital, Gondar, Northwest Ethiopia. HIV/AIDS. 2016;8:141.

11. Feleke R, Geda B, Teji Roba K, Weldegebreal F. Magnitude of antiretroviral treatment failure and associated factors among adult HIV-positive patients in Harar public hospitals, Eastern Ethiopia. SAGE Open Med. 2020;8:2050312120906076. doi:10.1177/ 2050312120906076

12. Bernheimer JM, Patten G, Makeleni T, et al. Paediatric HIV treatment failure: a silent epidemic. J Int AIDS Soc. 2015;18(1):20090. doi:10.7448/IAS.18.1.20090

13. Endalamaw A, Mekonnen M, Geremew D, Yehualashet FA, Tesera H, Habtewold TD. HIV/AIDS treatment failure and associated factors in Ethiopia: meta-analysis. BMC Public Health. 2020;20 (1):82. doi:10.1186/s12889-020-8160-8

14. Yihun BA, Kibret GD, Leshargie CT. Incidence and predictors of treatment failure among children on first-line antiretroviral therapy in Amhara Region Referral Hospitals, northwest Ethiopia 2018: a retrospective study. PLoS One. 2019;14(5):e0215300. doi: 10.1371 /journal.pone. 0215300

15. Ethiopia F. National Guidelines for Comprehensive HIV Prevention, Care and Treatment. AAMo Health; 2017.

16. Mekonnen E, Workicho A, Hussein N, Feyera T. Reasons and predictors for antiretroviral therapy change among HIV-infected adults at South West Ethiopia. BMC Res Notes. 2018;11(1):1-6. doi:10.1186/s13104-018-3470-y

17. Ethiopia MoHFDRo. National Guidelines for Comprehensive HIV Prevention, Care and Treatment. Ethiopia MoHFDRo; 2014.

18. Feola D, Thornton A, Garvy B. Effects of antiretroviral therapy on immunity in patients infected with HIV. Curr Pharm Des. 2006;12 (9):1015-1022. doi:10.2174/138161206776055886

19. Bacha T, Tilahun B, Worku A. Predictors of treatment failure and time to detection and switching in HIV-infected Ethiopian children receiving first line anti-retroviral therapy. BMC Infect Dis. 2012;12 (1):197.

20. Workneh N, Girma T, Woldie M, Michael KW, Lindstrom D. Immunologic and clinical outcomes of children on HAART: a Retrospective cohort analysis at Jimma University specialized hospital. Ethiop J Health Sci. 2009;19(2):2. doi:10.4314/ejhs. v19i2.69419

21. Assemie MA, Alene M, Ketema DB, Mulatu S. Treatment failure and associated factors among first line patients on highly active antiretroviral therapy in Ethiopia: a systematic review and meta-analysis. Global Health Res Policy. 2019;4(1):1-10. doi:10.1186/s41256-0190120-4

22. Zeleke A. Prevalence of antiretroviral treatment failure and associated factors in HIV infected children on antiretroviral therapy at Gondar University Hospital, retrospective cohort study. Int J Med Med Sci. 2016;8(11):125-132. doi:10.5897/IJMMS2015.1164 
23. Haile GS, Berha AB. Predictors of treatment failure, time to switch and reasons for switching to second line antiretroviral therapy in HIV infected children receiving first line anti-retroviral therapy at a Tertiary Care Hospital in Ethiopia. BMC Pediatr. 2019;19(1):37. doi:10.1186/s12887-019-1402-1

24. Yassin S, Gebretekle GB. Magnitude and predictors of antiretroviral treatment failure among HIV-infected children in Fiche and Kuyu hospitals, Oromia region, Ethiopia: a retrospective cohort study. Pharmacol Res Perspect. 2017;5(1):e00296. doi:10.1002/prp2.296

25. Kukoyi O, Renner L, Powell J, et al. Viral load monitoring and antiretroviral treatment outcomes in a pediatric HIV cohort in Ghana. BMC Infect Dis. 2015;16(1):58. doi:10.1186/s12879-0161402-9

26. Mgelea EM, Kisenge R, Aboud S. Detecting virological failure in HIV-infected Tanzanian children. $S$ Afr Med j. 2014;104 (10):696-699. doi:10.7196/SAMJ.7807

27. Costenaro P, Penazzato M, Lundin R, et al. Predictors of treatment failure in HIV-positive children receiving combination antiretroviral therapy: cohort data from Mozambique and Uganda. J Pediatric Infect Dis Soc. 2015;4(1):39-48. doi:10.1093/jpids/piu032

28. Bacha T, Tilahun B, Worku A. Predictors of treatment failure and time to detection and switching in HIV-infected Ethiopian children receiving first line anti-retroviral therapy. BMC Infect Dis. 2012;12 (1):1-8. doi:10.1186/1471-2334-12-197

29. Davies M-A, Moultrie H, Eley B, et al. Virologic failure and second-line antiretroviral therapy in children in South Africa-The IeDEA Southern Africa Collaboration. $J$ Acquired Immune Deficiency Syndromes. 2011;56(3):270. doi:10.1097/QAI.0b013 e3182060610

30. Buck WC, Kabue MM, Kazembe PN, Kline MW. Discontinuation of standard first-line antiretroviral therapy in a cohort of 1434 Malawian children. J Int AIDS Soc. 2010;13(1):31. doi:10.1186/1758-2652 $-13-31$

31. Osman FT, Yizengaw MA. Virological failure and associated risk factors among HIV/AIDS pediatric patients at the ART clinic of Jimma University Medical Center, Southwest Ethiopia. Open AIDS J. 2020;14(1):1. doi:10.2174/1874613602014010061

32. Rebouças MC, MOd S, Haguihara T, Brites C, Martins Netto E. Tuberculosis incidence among people living with HIV/AIDS with virological failure of antiretroviral therapy in Salvador, Bahia, Brazil. $\quad B r \quad J$ Inf Dis. 2017;21(5):562-566. doi:10.1016/j. bjid.2017.05.005

33. Kumar P. Adult pulmonary tuberculosis as a pathological manifestation of hyperactive antimycobacterial immune response. Clin Transl Med. 2016;5(1):1-7. doi:10.1186/s40169-016-0119-0
34. Cissé A-M, Laborde-Balen G, Kébé-Fall K, et al. High level of treatment failure and drug resistance to first-line antiretroviral therapies among HIV-infected children receiving decentralized care in Senegal. BMC Pediatr. 2019;19(1):47. doi:10.1186/s12887-019$1420-z$

35. Kamya MR, Mayanja-Kizza H, Kambugu A, et al. Predictors of long-term viral failure among Ugandan children and adults treated with antiretroviral therapy. JAIDS J Acquired Immune Deficiency Syndromes. 2007;46(2):187-193. doi:10.1097/QAI.0b013e3 $1814278 \mathrm{c} 0$

36. Penot P, Héma A, Bado G, et al. The vulnerability of men to virologic failure during antiretroviral therapy in a public routine clinic in Burkina Faso. J Int AIDS Soc. 2014;17(1):18646. doi:10.7448/ IAS.17.1.18646

37. Nega J, Taye S, Million Y, Rodrigo C, Eshetie S. Antiretroviral treatment failure and associated factors among HIV patients on first-line antiretroviral treatment in Sekota, northeast Ethiopia. AIDS Res Ther. 2020;17(1):1-9. doi:10.1186/s12981-020-00294-Z

38. Misganie YG, Yizengaw A, Likie A, et al. Rate and predictors of treatment failure among pediatric population taking highly active antiretroviral therapy in Ethiopia. medRxiv. 2019;19005538.

39. Prabhakar B, Banu A, Pavithra H, Chandrashekhara P, Sasthri S. Immunological failure despite virological suppression in HIV seropositive individuals on antiretroviral therapy. Indian $j$ Sexually Transmitted Dis AIDS. 2011;32(2):94. doi:10.4103/0253-7184.85412

40. Martinez-Picado J, Deeks SG, Persistent HIV-1. replication during antiretroviral therapy. Curr Opin HIV AIDS. 2016;11(4):417. doi:10.1097/COH.0000000000000287

41. Liégeois F, Vella C, Eymard-Duvernay S, et al. Virological failure rates and HIV-1 drug resistance patterns in patients on first-line antiretroviral treatment in semirural and rural Gabon. $J$ Int AIDS Soc. 2012;15(2):17985. doi:10.7448/IAS.15.2.17985

42. Sibhat M, Kassa M, Gebrehiwot H. Incidence and predictors of treatment failure among children receiving first-line antiretroviral treatment in general hospitals of two zones, Tigray, Ethiopia, 2019. Pediatr Health Med Ther. 2020;11:85. doi:10.2147/PHMT.S243656

43. Emmett SD, Cunningham CK, Mmbaga BT, et al. Predicting virologic failure among HIV-1-infected children receiving antiretroviral therapy in Tanzania: a cross-sectional study. J Acquir Immune Defic Syndr. 2010;54(4):368. doi:10.1097/QAI.0b013e3181cf4882

44. Sebunya R, Musiime V, Kitaka SB, Ndeezi G. Incidence and risk factors for first line anti retroviral treatment failure among Ugandan children attending an urban HIV clinic. AIDS Res Ther. 2013;10 (1):1-10. doi:10.1186/1742-6405-10-25
HIV/AIDS - Research and Palliative Care

\section{Publish your work in this journal}

HIV/AIDS - Research and Palliative Care is an international, peerreviewed open-access journal focusing on advances in research in HIV, its clinical progression and management options including antiviral treatment, palliative care and public healthcare policies to control viral spread. The manuscript management system is completely online and includes a very quick and fair peer-review system, which is all easy to use. Visit http://www.dovepress.com/testimonials.php to read real quotes from published authors. 